\title{
Alleviation of a Selective Age-Related Relational Memory Deficit in Mice by Pharmacologically Induced Normalization of Brain Retinoid Signaling
}

\author{
Nicole Etchamendy, ${ }^{1}$ Valérie Enderlin, ${ }^{2}$ Aline Marighetto, ${ }^{1}$ Rose-Marie Vouimba, ${ }^{1}$ Véronique Pallet, ${ }^{2}$ \\ Robert Jaffard, ${ }^{1}$ and Paul Higueret ${ }^{2}$ \\ ${ }^{1}$ Laboratory of Cognitive Neurosciences, Unité Mixte de Recherche Centre National de la Recherche Scientifique 5106, \\ and 'Laboratory of Nutrition and Cellular Signalization, Unité sous contrat Institut National de la Recherche Agronomique, \\ University of Bordeaux 1, 33405 Talence Cedex, France
}

\begin{abstract}
Vitamin $A$ and its derivatives, the retinoids, have been implicated recently in the synaptic plasticity of the hippocampus and might therefore play a role in associated cognitive functions. Acting via transcription factors, retinoids can regulate gene expression via their nuclear receptors [retinoic acid receptors (RARs) and retinoid $X$ receptors]. In a series of experiments, the present study investigated the possible role of age-related downregulation of retinoid-mediated transcription events in the cognitive decline seen in aged mice. We observed that the brain (and hippocampal) levels of retinoid receptors and the expression of specific associated target genes were restored to presenescent (adult) levels in aged mice after acute administration (150 $\mu \mathrm{g} / \mathrm{kg}$, s.c.) of retinoic acid (RA). These effects of RA, however, could be abolished by the coadministration of an RAR antagonist. RA was also demonstrated to alleviate the agerelated deficit in the CA1 long-term potentiation efficacy of
\end{abstract}

aged mice in vivo. Moreover, RA was found to alleviate completely the performance deficit of aged mice to the control level in a two-stage spatial discrimination paradigm designed to assess relational memory. This promnesic effect of RA was again susceptible to abolition by RAR antagonist treatment. The parallel molecular, cellular, and behavioral correlates associated with the decrease of retinoid receptor expression and its normalization demonstrated here suggest that the fine regulation of retinoid-mediated gene expression is fundamentally important to optimal brain functioning and higher cognition. Specifically, a naturally occurring dysregulation of retinoidmediated molecular events might be a potential etiological factor for cognitive deterioration during senescence.

Key words: cognitive aging; retinoic acid receptors; vitamin A; neurogranin; synaptic plasticity; LTP; learning; $R A R$; $R X R$
Vitamin A is a micronutrient with an unusually wide scope of biological actions that includes morphogenesis, vision, immune function, reproduction (Malik et al., 2000), and a major role in the fetal development of the nervous system (Maden et al., 1998). In the adult brain, the recent cartography of multiple nuclear receptors for the vitamin A metabolite retinoic acid (RA) by Krezel et al. (1999) has provided the basis for investigation into the potential role of vitamin $\mathrm{A}$ in the maintenance of mature nervous function (Malik et al., 2000). Retinoic acid receptors ( $\operatorname{RAR} \alpha, \beta$, and $\gamma)$ and retinoid $\mathrm{X}$ receptors $(\operatorname{RX} \operatorname{R} \alpha, \beta$, and $\gamma$ ) are DNAbinding proteins that, after activation by specific retinoid ligands, induce gene transcription by interacting with distinct promoter sequences in the target genes (Kastner et al., 1995). Knock-out studies have shown that these receptors (viz., $\operatorname{RAR} \beta$ and $\operatorname{RXR} \gamma$ ) (Chiang et al., 1998) as well as certain target genes coding for neuronal proteins, such as neurogranin ( $\mathrm{RC} 3), \mathrm{a} \mathrm{Ca}^{2+}$-sensitive calmodulin-binding protein (Iñiguez et al., 1994; Pak et al., 2000),

\footnotetext{
Received Feb. 23, 2001; revised May 29, 2001; accepted May 30, 2001.

This research was supported by the Centre National de la Recherche Scientifique and by the Conseil Régional d'Aquitaine. We thank Dr. U. Reichert (Galderma Laboratory, Sofia-Antipolis, France) for donating the RAR antagonist CD3106 and Drs. B. K. Yee, T. Durkin, and Y. Cho for their helpful comments on this manuscript and suggestions for the English revision.

Correspondence should be addressed to Dr. Robert Jaffard, Laboratory of Neurosciences Cognitives, Unité Mixte de Recherche 5106, Université de Bordeaux 1, Avenue des Facultés, 33405 Talence Cedex, France. E-mail: jaffard@neurocog. u-bordeaux.fr.

Copyright (ㄷ) 2001 Society for Neuroscience $\quad 0270-6474 / 01 / 216423-07 \$ 15.00 / 0$
}

play a critical role in hippocampal long-term potentiation (LTP), the most widely studied form of synaptic plasticity thought to underlie information storage (McNaughton and Morris, 1987). A similar conclusion can also be derived from studies in mice deprived of vitamin A (Jacobs et al., 2000), and together the data strongly suggest a likely involvement of brain retinoid signaling in higher cognitive functions.

It has also been reported that the levels of mRNA for brain retinoid ( $\mathrm{RAR} \beta$ and $\mathrm{RXR} \beta / \gamma$ ) nuclear receptors and the expression of certain target genes (including RC3) are reduced in aged mice by $20-30 \%$ relative to the levels in adults. Furthermore, such senescence-related reductions are susceptible to reversal by acute systemic RA (Enderlin et al., 1997). Prompted by these initial findings, the present study was undertaken to evaluate the extent to which the reduction in retinoid-related molecular signaling, despite being of moderate magnitude, might contribute to the cognitive and associated physiological alterations seen in aged mice.

Because previous studies have attributed to retinoid receptors an essential role in hippocampal synaptic plasticity, we first examined the effects of RA administration on the efficacy of LTP in CA1 induced by commissural stimulation in vivo. We then evaluated our principal hypothesis of an association between the downregulation of retinoid signaling and the emergence of a specific cognitive impairment in aged mice. To this end, we used a two-stage behavioral paradigm that can distinguish between the expression of declarative memory (which is impaired in senes- 
cence) and the expression of procedural memory (which remains primarily intact in senescence) related to the same piece of learned material (Marighetto et al., 1999, 2000). This dissociation between the two forms of memory expression is also noted in human senescence, and the specific impairment in declarative memory is believed to stem from a dysfunction of the hippocampal region (Gabrieli, 1996).

Current theories suggest that declarative memory is critically dependent on the formation of a complex and coherent memory trace in which the configuration and inter-relationship among various aspects of past experience are represented (Johnson, 1992; Eichenbaum, 1997). Such complex relational representations enable two unique features of declarative memory expression: (1) the ability to compare and contrast separately acquired information and (2) the inferential use of past memories in novel situations (i.e., flexibility) (Cohen, 1984). The behavioral paradigm used here was specifically designed to assess these two features of declarative memory and is able to capture the selective declarative memory deficit of aged mice (Marighetto et al., 1999) as well as that of mice with hippocampal lesions (Etchamendy et al., 1999). Using this paradigm, we evaluated the potential promnesic effect of RA on declarative memory expression. In addition, we investigated whether such an effect could be antagonized by a blockade of retinoic acid receptors. If so, it would be consistent with the hypothesis that the promnesic effect of RA was mediated via an increase in the expression of brain (and hippocampal) retinoid receptors and their associated target genes in aged mice.

\section{MATERIALS AND METHODS}

Animals and drug preparation. The subjects were naive male mice of the C57BL/6 Jico inbred strain obtained from IFFA Credo (Lyon, France). They belonged to two distinct age ranges: $\sim 21-23$ months old (aged) and $\sim 4-5$ months old (adult). Mice of the latter age range served as presenescent controls. They were housed in a temperature-controlled and ventilated animal room under a $12 \mathrm{hr}$ light/dark cycle. Mice destined for behavioral testing were placed on a restricted diet with their body weight maintained at $90 \%$ of their free-feeding level. All other mice were fed ad libitum.

Retinoic acid (Sigma, St. Louis, MO) and the RAR antagonist (CD3106; gift of Dr. U. Reichert) were dissolved in a vehicle solution containing polyethylene glycol, $\mathrm{NaCl}(0.9 \%)$, and ethanol mixed in a proportion of 70:20:10 by volume. CD3106 is also referred to as AGN193109 by Klein et al. (1996).

We used a dose of retinoic acid $(150 \mu \mathrm{g} / \mathrm{kg})$ that has been shown to be effective in reversing the age-related hypoexpression of brain retinoid signaling (Enderlin et al., 1997) and a dose of CD3106 $(1 \mathrm{mg} / \mathrm{kg})$ that is effective in blocking this reversal when coadministered. Both drugs were administered via the subcutaneous route.

In the electrophysiological study, three groups of mice of equal size $(n=6)$ were constituted: aged $+\mathrm{RA}$, adult + vehicle, and aged + vehicle groups. They were injected daily with RA or vehicle solution for $4 \mathrm{~d}$ before high-frequency stimulation.

In the behavioral experiment, there were four groups of mice: (1) aged + RA group ( $n=10$; aged mice receiving an RA injection), (2) aged $+\mathrm{RA}+\mathrm{CD} 3106$ group $(n=6$; aged mice receiving injection of a mixture containing RA and the RAR antagonist CD3106) (Klein et al., 1996), (3) aged + vehicle group $(n=8$; aged mice receiving a vehicle injection), and (4) adult + vehicle group $(n=8$; adult mice receiving a vehicle injection). Daily injection began $4 \mathrm{~d}$ before behavioral testing commenced and continued until the end of behavioral testing. Injection was always made between 18:00 and 19:00 hr, whereas behavioral testing was conducted between 10:00 and 16:00 hr.

For reverse transcription (RT)-PCR analysis, two sets of subjects were used. The first set consisted of the mice that were used in the behavioral test and killed at the end of behavioral testing. Their hippocampi were submitted to RT-PCR analysis. The second set of mice was also divided into four groups $(n=6)$ according to age and drug treatment, similar to those in the first set. However, the second set of mice was never behav-
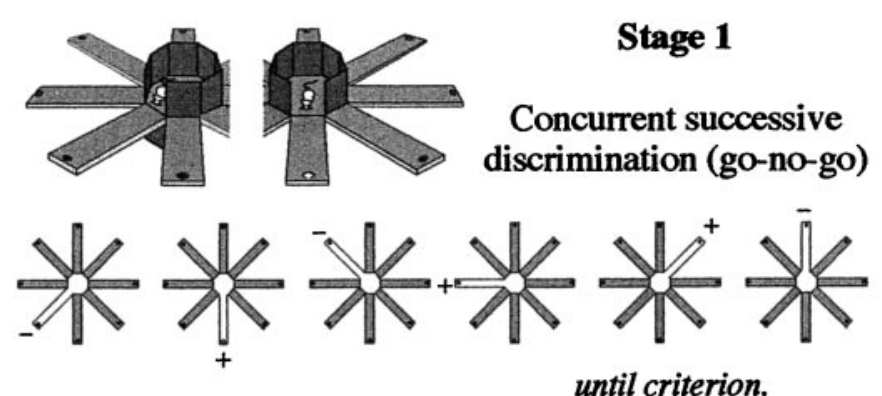

then,

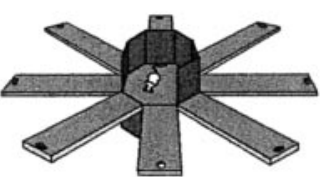

Stage 2

\section{Concurrent simultaneous (two-choice) discrimination}
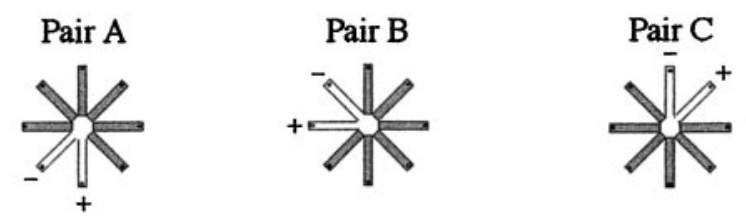

Figure 1. Design of the behavioral procedure.

iorally tested and was killed after 4 consecutive days of injection. Thus, the analysis of the second set of mice allows an evaluation of the effects of age and drug in naive subjects, free from any influence because of behavioral training. For the second (nontrained) set, RT-PCR analysis was performed either for the hippocampus alone or for the whole brain.

Learning and memory testing. The apparatus was a fully automated eight-arm radial maze, $150 \mathrm{~cm}$ in diameter, as described previously by Marighetto et al. (1999). The testing procedure is depicted in Figure 1. Before training on the discrimination task, the mice were habituated to the apparatus daily, with free access to all arms, for $2 \mathrm{~d}$. For discrimination training, each subject was individually assigned a set of six adjacent arms. Of these, three served as positive (always baited) arms, and the remaining three served as negative (never baited arms).

Animals first acquired (stage 1) the valence or reward contingencies associated with each arm. For this purpose, subjects were tested continuously in a series of trials in which they were confronted with only one arm (either rewarded or not rewarded) open at a time. On each daily session, each arm was presented four times (i.e., 24 trials). Go-no-go discriminative performance was evaluated by the ratio between the median latency to enter nonrewarded (negative) arms and rewarded (positive) arms. A ratio above unity indicates that the mouse was more ready to enter rewarded arms than nonrewarded ones. Stage 2 began when performance based on this measure attained the criterion level. The criterion was defined as an overall ratio exceeding 1.5 over 2 consecutive days and exceeding 1.3 for each of the three pairs of arms to be designated at stage 2 .

At stage 2, the reward contingencies remained unchanged, but the six arms were grouped into three pairs of adjacent arms of opposite valence (pairs A-C). In each trial, the subject was confronted with access to two adjacent arms of opposite valence (either of pairs A-C). A choice was considered to be made when the subject had reached the food well of an arm; this also triggered the closure of the door to the alternative arm. The trial was finished as soon as the subject returned to the central platform. Each daily session consisted of 20 consecutive trials comprising alternate presentations of pairs $\mathrm{A}-\mathrm{C}$ according to a pseudorandom sequence. Two-choice discriminative performance was measured by the percentage correct (choice of the positive arm) and expressed as blocks of $2 \mathrm{~d}$.

Biochemical analysis. The amounts of mRNAs coding for retinoic acid receptors ( $\operatorname{RAR} \beta$ and $\operatorname{RXR} \beta / \gamma$ ), and for two protein products of their target genes, the tissue-type transglutaminase (tTG) (Chiocca et al., 1989) and RC3, were measured in the whole brain, as well as in the 
hippocampus, for RXR $\beta / \gamma$ and RC3. The four groups of mice were killed either on the day after the fourth day of drug administration (i.e., before the beginning of behavioral training) or after the end of behavioral testing (i.e., after $25 \mathrm{~d}$ of drug administration). Their brain or hippocampi were removed and stored at $-80^{\circ} \mathrm{C}$. mRNAs were quantified by RT-PCR assay using $\beta$-actin as the internal control. The stability of $\beta$-actin mRNA levels (Dong et al., 1990; Rogue et al., 1993) was checked in all experimental conditions using a competitive RT-PCR method and the PCR MIMIC Construction Kit (Clontech, Palo Alto, CA). Total mRNA was extracted using the method described by Chomczynski and Sacchi (1987). cDNA preparation, PCR analysis, and quantitative determination of PCR products were performed as described previously by Alfos et al. (1996). Aliquots of the PCR reaction were sampled after each of the 7th through 24th amplification cycles. Amplification products were measured after their resolution by electrophoresis. The determination of the proportion of $\operatorname{RAR} \beta, \operatorname{RXR} \beta / \gamma, \mathrm{RC} 3$, and tTG mRNA to that of $\beta$-actin was calculated according to the method of Chelly et al. (1990) using a semilogarithmic representation of the relative extent of amplification measured by counting the amount of incorporated ${ }^{32} \mathrm{P}$. The oligonucleotide primers for $\operatorname{RAR} \beta, \operatorname{RXR} \beta / \gamma$, tTG, and $\operatorname{RC} 3$ were as described previously by Enderlin et al. (1997).

In vivo electrophysiology. Mice were anesthetized with Avertin (10 $\mathrm{ml} / \mathrm{kg}$, i.p.). The stimulating and recording electrodes were made of two twisted pairs of platinum-iridium wires ( $90 \mu \mathrm{m}$ in diameter) insulated except at the tip. By means of stereotaxic surgery, one electrode was positioned in the ventral hippocampal commissure $(0.5 \mathrm{~mm}$ posterior to bregma and $0.3 \mathrm{~mm}$ lateral to the midline), and the other was in the contralateral pyramidal layer of CA1 $(1.8 \mathrm{~mm}$ posterior to bregma and $1.3 \mathrm{~mm}$ lateral to the midline). The electrode positions were adjusted to maximize evoked field potentials, and then they were fixed with dental cement. Afterward, the animals were allowed to recover for $6 \mathrm{~d}$. They were then habituated to the recording conditions for $3 \mathrm{~d}$ before recording sessions began.

CA1 field potentials evoked by single-pulse commissural stimulation ( $0.1 \mathrm{msec}$ biphasic pulses) were recorded through junction field effect transistor operational amplifiers placed on the head of the animals and amplified, displayed on an oscilloscope, and recorded by a microcomputer for on-line averaging (each average was obtained with 20 responses at $0.2 \mathrm{~Hz}$ ). The population spike was measured between the early positive peak and the large negative peak of the evoked potential. Stimulation intensity was adjusted to produce a population spike that was $30 \%$ of the maximum amplitude obtained from the baseline inputoutput curves. The baseline was established over a $2 \mathrm{~d}$ period (two recording sessions of $5 \mathrm{~min} / \mathrm{d})$. After the last $5 \mathrm{~min}$ baseline period, high-frequency stimulation (HFS) of the commissural path consisting of one train of 100 pulses was delivered at $100 \mathrm{~Hz}$. The post-tetanus amplitudes of population spikes were followed every $5 \mathrm{~min}$ for $1 \mathrm{hr}$ using the same single-pulse test that was used for the establishment of baseline.

After completion of the experiment, all mice were given an overdose of Avertin and perfused with saline $(0.9 \%)$ followed by formol saline $(10 \%)$. The exact placement of the electrodes was then verified by conventional histology.

Statistical analysis. Data were submitted to ANOVAs with the appropriate design. Post hoc comparisons were performed using the Scheffe $F$ test.

\section{RESULTS}

\section{Electrophysiological data}

As shown in Figure $2 b$, a $1 \mathrm{sec}$ train of HFS (at $100 \mathrm{~Hz}$ ) of the ventral commissure induced a potentiation of the population spike in hippocampal CA1. LTP was evident in all groups, because the mean population spike amplitudes were significantly increased with respect to baseline (repeated measures followed by Scheffe $F$ test, all $p$ values $<0.05$ ). However, the potentiation seen across time after HFS was significantly different among the three groups $\left(F_{(2,16)}=3.86 ; p=0.043\right)$. Specifically, LTP seen in the aged + vehicle group was significantly weaker than that in the adult + vehicle group $\left(F_{(1,10)}=4.99 ; p=0.049\right)$. This deficit in LTP was partially reversed in the aged mice treated with RA over the previous $4 \mathrm{~d}$. Indeed, the mean population spike amplitudes seen across time after HFS were significantly increased in the aged + RA group compared with the aged + vehicle group

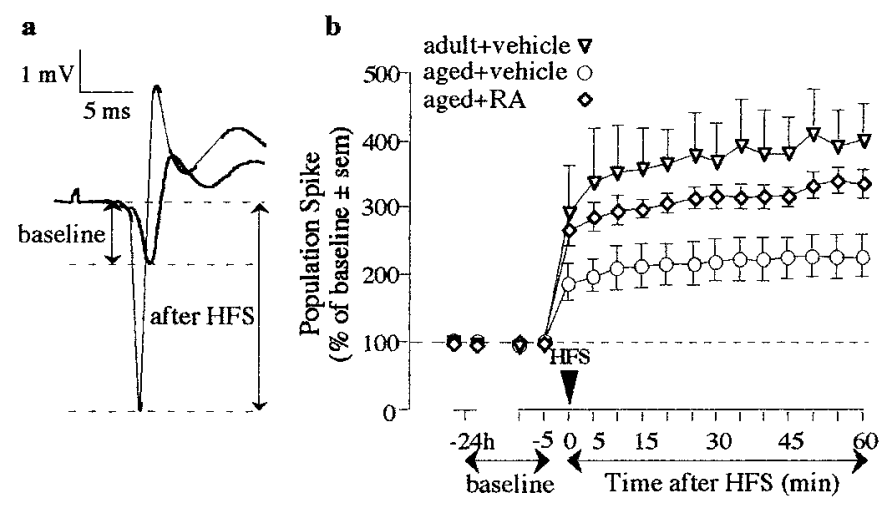

Figure 2. $a$, Representative records of the population spike in the CA1 region of the hippocampus before and after HFS of the contralateral ventral hippocampal commissure. $b$, The average amplitude of the population spike normalized to the average baseline value before HFS.

$\left(F_{(1,11)}=8.71 ; p=0.013\right)$ and were close to the amplitudes recorded in the adult + vehicle group.

\section{Behavioral data}

During stage 1 of behavioral testing, when the arms were presented one by one following a successive go-no-go discrimination procedure, neither the effect of age nor drugs significantly affected performance. There was no significant between-groups difference in the mean $( \pm$ SEM) number of sessions needed to attain criterion performance (adult + vehicle, $10.25 \pm 0.91$; aged + vehicle, $9.75 \pm 0.91$; aged + RA, $11.60 \pm 0.81$; aged + $\left.\mathrm{RA}+\mathrm{CD} 3106,10.17 \pm 1.05 ; F_{(3,28)}=0.89 ; p=0.46\right)$. Moreover, as shown in Figure 3, left, all groups displayed a similar response accuracy across the first and last six sessions as evaluated by measures of the no-go/go enter-latency ratio. Specifically, an ANOVA performed on this measure of performance across the first six sessions revealed no significant between-groups difference $\left(F_{(3,28)}=0.39 ; p=0.76\right)$ with no significant improvement of performance across sessions $\left(F_{(5,140)}=1.63 ; p=0.16\right)$ or group $\times$ session interaction $\left(F_{(15,140)}=1.17 ; p=0.30\right)$. The same analysis performed across the last six sessions showed that all groups learned to distinguish between the positive (rewarded) and negative (nonrewarded) arms as evidenced by their progressive increased readiness to enter positive relative to negative arms. An ANOVA performed on these data yielded a significant effect of sessions $\left(F_{(5,140)}=22.63 ; p<0.001\right)$ but no evidence of any between-groups difference $\left(F_{(3,28)}=0.13 ; p=0.94\right)$ or group $\times$ session interaction $\left(F_{(15,140)}=0.32 ; p=0.99\right)$. Thus, all groups were performing at a similar level (group, $\left.F_{(3,28)}=0.07 ; p=0.97\right)$ with a mean enter-latency ratio between 2.19 and 2.40 , which was significantly above chance ( $p<0.001$ for each group), over the last two training sessions preceding stage 2 (Fig. 3 , middle).

In contrast, significant between-groups differences emerged $\left(F_{(3,28)}=8.99 ; p<0.001\right)$ when the mice were confronted with the three simultaneous discriminations composed of the six arms that were presented individually to them in stage 1 (Fig. 3, right). The vehicle-treated aged mice failed to translate their acquired preference for single arms into a choice between one positive and one negative arm presented as an explicit pair. With a mean percentage correct rate of $50.4 \%$, they were performing significantly poorer (post hoc comparison, $p<0.001$ ) than were adult controls that attained a level of $72.2 \%$ correct. Remarkably, RA-treated aged mice showed no sign of such a deficit (averaged at $68.4 \%$ correct) and significantly outperformed vehicle-treated 
Stage 1

(successive go-nogo discrimination)
Stage 2

(simultaneous discrimination)

acquisition

last two sessions

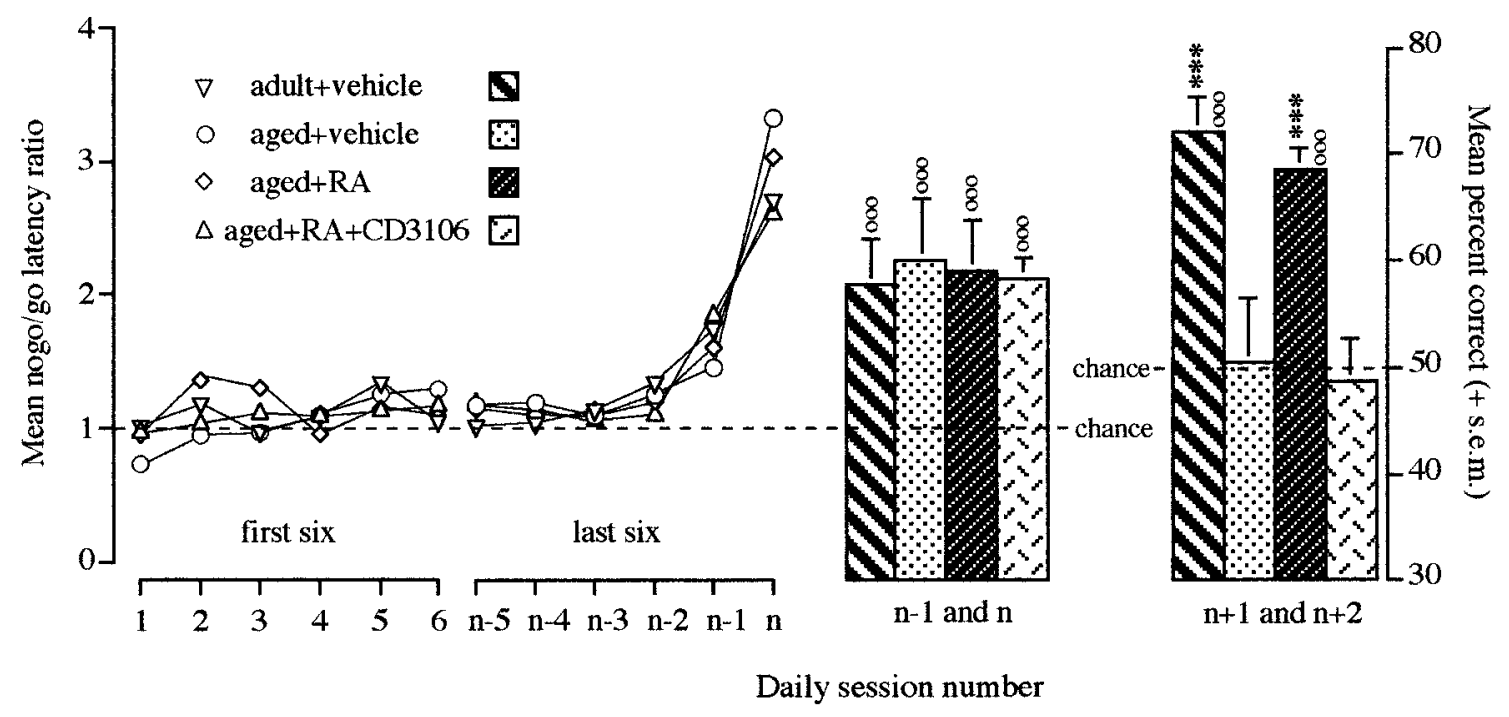

Figure 3. Left, Progression of the go-no-go discriminative performance evaluated by the no-go/go enter-latency ratio over the first six (1-6) sessions (i.e., the presently observed minimum number of sessions required to attain the criterion) and the last six $(n-5$ to $n)$ sessions of training before reaching criterion in stage 1. Middle, Mean no-go/go enter-latency ratio over the last two sessions $(n-1, n)$ of stage 1. Right, Two-choice discriminative performance expressed as the mean percentage correct over the two daily sessions of stage $2(n+1, n+2)$. Post hoc Scheffe test: *** $p<0.001$ versus aged + vehicle group; ${ }^{\circ 0} p<0.001$ versus chance $(50 \%)$.

aged mice (post hoc comparison, $p<0.001$ ). Furthermore, this promnesic effect of RA was entirely abolished by the coadministration of the RAR antagonist CD3106. The aged + RA + CD3106 group attained an average correct rate of $48.7 \%$ and was not different from the aged + vehicle group ( post hoc comparison, $p=0.99$ ).

\section{Biochemical data}

One-way ANOVAs performed on biochemical data relative to the whole brain of mice submitted to $4 \mathrm{~d}$ of treatment revealed significant between-groups differences (all $F_{(3,11)}>9.74$; all $p$ values $<0.05)$. The aged + vehicle group exhibited significantly lower levels of brain mRNAs coding for retinoid receptors (RAR $\beta,-27 \%$; RXR $\beta / \gamma,-21 \%$ ), for tTG (-26\%), and for RC3 $(-20 \%)$ relative to the levels of the adult + vehicle group (post hoc comparisons, all $p$ values $<0.05$ ). On the other hand, the mRNA contents in the aged + RA group were significantly increased relative to their age-matched controls (post hoc comparisons, aged + RA vs aged + vehicle, all $p$ values $<0.05)$ and were at a level comparable with those seen in adult mice (post hoc comparisons, aged + RA vs adult + vehicle, all $p$ values $>0.05)$. This RA-induced normalization of mRNA contents was almost completely blocked by the coadministration of the RAR antagonist CD3106 (post hoc comparisons, aged + RA + CD3106 vs aged + vehicle, all $p$ values $>0.05$; aged $+\mathrm{RA}+\mathrm{CD} 3106$ vs aged + RA, all $p$ values $<0.05$ ) (Fig. $4 a$ ). A similar pattern of results was observed in the hippocampus (Fig. $4 b$; all $F_{(3,11)}>$ 26.1; all $p$ values $<0.001$ ).

The biochemical data derived from the behaviorally tested mice conformed to the results described above (all $F_{(3,11)}>8.38$; all $p$ values $<0.008)$. This indicated that, irrespective of the time of death, vehicle-treated aged mice displayed lower levels of mRNAs coding for either RXR $\beta / \gamma(-39 \%)$ or RC3 $(-31 \%)$ relative to the levels of the adult + vehicle group. Two-way ANOVAs incorporating data from both sets of mice yielded an overall main effect of age for both variables [RX R, $F_{(1,8)}=55.39$; $p<0.001$; RC3, $\left.F_{(1,8)}=137.44 ; p<0.001\right]$ with no significant interaction between age and time of death $\left[\mathrm{RXR}, F_{(1,8)}=1.46\right.$; $p=0.26$; RC3, $\left.F_{(1,8)}=1.15 ; p=0.31\right]$. RA administration alone almost totally abolished the age-related decrease in mRNA contents [effect of treatment, $\operatorname{RXR}\left(F_{(2,12)}=20.62 ; p<0.001\right)$ and $\left.\operatorname{RC} 3\left(F_{(2,12)}=31.12 ; p<0.001\right)\right]$, and this effect was again similar regardless of the time of death [treatment $\times$ time of death interaction, $\operatorname{RXR}\left(F_{(2,12)}=0.05 ; p=0.95\right)$ and $\operatorname{RC} 3\left(F_{(2,12)}=\right.$ $0.41 ; p=0.67)]$. Finally, this reversal effect of RA was totally blocked by the coadministration of CD3106 (post hoc comparisons, aged $+\mathrm{RA}+\mathrm{CD} 3106$ vs aged $+\mathrm{RA}, p$ values $<0.05$; aged $+\mathrm{RA}+\mathrm{CD} 3106$ vs aged + vehicle, $p$ values $>0.05)$ (Fig. 4b).

\section{DISCUSSION}

\section{Long-term potentiation}

First, the present data showed that the potentiation of the CA1 population spike induced by HFS of the ventral commissure was reduced in aged mice. This deficit is in agreement with a previous experiment using a similar brief HFS protocol to induce LTP (see Geinisman et al., 1995). Second, we demonstrated that this agerelated deficit in LTP amplitude was ameliorated by the administration of RA. Because the dose of RA used here was also effective in restoring the $30 \%$ age-related decrease in retinoid signaling (as shown by the biochemical analyses) to the normal (adult) level, our data suggest that the initial moderate retinoid hypoexpression might be sufficient to produce the significant deficiency in synaptic plasticity seen in our vehicle-treated aged mice. 
a

(whole brain)

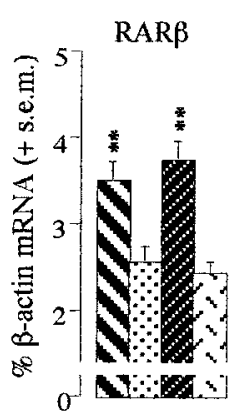

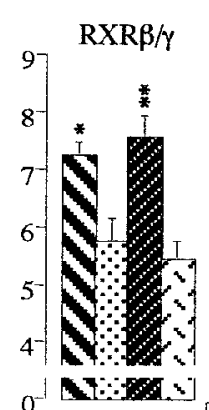

adult+vehicle aged $+\mathrm{RA}$

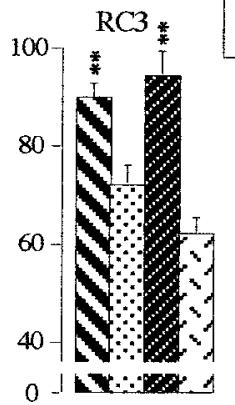

aged $+\mathrm{RA}+\mathrm{CD} 3106$

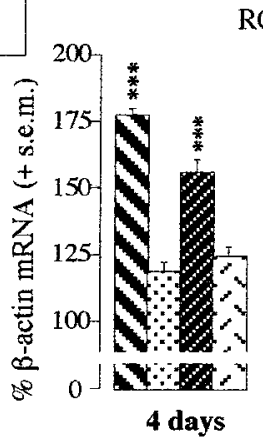

b (hippocampus)

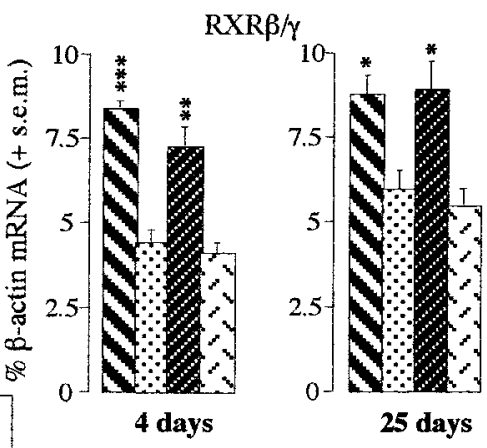

$\mathrm{RC3}$

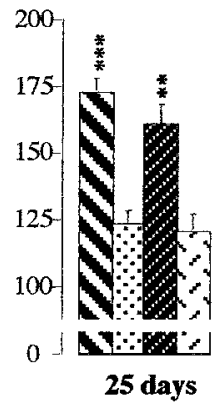

Figure 4. $a$, Whole-brain mRNAs in mice killed $24 \mathrm{hr}$ after the fourth daily drug treatment. $b$, Hippocampal mRNAs in mice killed either $24 \mathrm{hr}$ after the fourth daily administration of treatments (i.e., before the beginning of behavioral training) or after completion of testing in stage 2 (i.e., the day after the 25 th daily administration of treatments). All values are expressed as the mean \pm SEM of measures derived from three independent samples $(n=3)$. Each sample unit consisted of two pooled whole brains or two pooled hippocampi (i.e., a total of 6 animals). Post hoc Fisher tests: $* p<0.05 ; * * p<0.01$; $* * * p<0.001$; all significantly different from the aged + vehicle group.
In this respect, our data complement and further extend previous studies in knock-out mice that demonstrated, in vitro, an LTP deficit in mice not expressing $\operatorname{RAR} \beta, \operatorname{RAR} \beta / \operatorname{RXR} \gamma$ (Chiang et al., 1998), or RC3 (Pak et al., 2000). Our data suggest that normal mice with a natural, yet more limited, retinoid hypoexpression also exhibit significant functional alterations in hippocampal synaptic plasticity that can be reduced by pharmacological normalization of retinoid signaling. Thus, not only are retinoid-mediated transcription events involved in the molecular mechanisms underlying functional synaptic plasticity (as suggested by knock-out studies), but also a precise control in these nuclear events is a prerequisite for the functional integrity of such neural plasticity.

\section{Effects of RA administration on the cognitive and associated retinoid-signaling dysfunction in aged mice}

In sum, our biochemical and behavioral data show that (1) aged mice with a reduced expression of brain $\operatorname{RAR} \beta$ and $\operatorname{RXR} \beta / \gamma$ mRNAs relative to those of adult mice were severely and specifically impaired in stage 2 of the discrimination task, (2) reversal of the age-related hypoexpression of brain retinoid receptors by RA administration was accompanied by a complete restoration of this behavioral impairment, and (3) the promnesic effect of RA was abolished by the coadministration of a selective RAR antagonist that concomitantly blocked the RA-induced normalization of retinoid signaling, hence demonstrating that this effect was mediated via brain retinoid receptors.

The selectivity of the cognitive deficit seen in our aged mice in stage 2 of the task as well as its reversal by RA renders unlikely the possibility that the amnesic effect of age and the promnesic effect of the drug are simply caused by their nonspecific effects on affect, motivation, perception, or motor control. Specifically, such nonspecific effects would have similarly influenced performance in both stage 1 and stage 2 because the basic requirements of the task were the same in both stages. It follows that the deleterious effect of age, and its reversal by RA, must be cognitive in nature. These contrasting effects should be taken as further evidence that these two versions of the position discrimination (i.e., stage 1 and stage 2) rely on distinct and dissociable memory systems (Etchamendy et al., 1999; Marighetto et al., 1999, 2000). The go-no-go discrimination in stage 1 involves separate unitary responses to individual arms and therefore can be achieved using elemental stimulus-response associations, forms of procedural and/or implicit memory that are independent of the hippocampal system. Conversely, the transfer to the two-choice problems at stage 2 entails comparisons between information acquired separately. Effective transfer would require the use of relational representations of past experiences and the functional integrity of the hippocampal formation (Eichenbaum et al., 1992).

\section{Possible cellular and molecular mechanisms involved} in the reversal of the age-related cognitive deficit by RA administration

The first line of explanation is based on the involvement of retinoid-mediated transcription events in synaptic plasticity. Because the formation of relational mnemonic representations is considered to be critically dependent on the Hebbian plastic properties of hippocampal synapses (Wallenstein et al., 1998), the observed promnesic effect of RA might stem from some restoration of the well documented age-related alterations in hippocampal synaptic plasticity (Barnes, 1994). In this respect, the RAinduced normalization of the age-related retinoid hypoexpression would reestablish a sufficient level of downstream-activated protein products for supporting the functional synaptic properties required for relational memory processing. RC3 is one of the numerous synaptic protein products of the retinoid-activated target genes [others include NMDA receptors (Younkin et al., 1993) or synaptophysin (Gaetano et al., 1992)]. Because the 
content of these proteins in the brain is decreased via the aging process (Tamaru et al., 1991; Chen et al., 1998; but see Nicolle et al., 1999), they could well be implicated in the observed effects of RA here.

However, because of the large profile of genes the expression of which is under the control of nuclear retinoid receptors (Mangelsdorf, 1994), other related mechanisms could be considered as likely candidates for explaining our present results. Specifically, numerous studies have provided evidence that RA exerts a direct effect on the expression of a variety of cholinergic-specific proteins (Pedersen et al., 1995; Malik et al., 2000) and on the expression of neurotrophic factors (e.g., NGF) that, in turn, could be involved in the survival of cholinergic neurons (Korsching, 1993; Rylett and Williams, 1994; Corcoran and Maden, 1999). This is of particular interest because a decrease in central cholinergic neurotransmission has been one of the most consistently advanced hypothesis to account for the cognitive impairment associated with aging and certain age-related neurodegenerative diseases (Gallagher and Colombo, 1995).

Regardless of the cellular mechanisms involved, our results show that a $20-30 \%$ change in the expression of brain (and hippocampal) retinoid receptors is associated with significant alterations in certain target-gene mRNA contents, hippocampal LTP, and a hippocampal-dependent form of memory. These molecular, cellular, and behavioral correlates suggest that, although such alterations in retinoid signaling might be considered as moderate in magnitude, they can have significant consequences at various levels of brain function or organization. Our results thus point to retinoid hyposignaling as a potential cause of cognitive aging. This is consistent with recent data showing that a similar retinoid-signaling hypofunction, induced by a vitamin A-deprived diet in adult mice, also results in the same specific cognitive impairment as seen in our aged mice here (Etchamendy et al., 2000). Furthermore, this hypothesis is in line with the general principle "that the signals transduced by cells during growth and physiologic activity are the same as those that become overloaded during pathologic events and aging" (Malik et al., 2000). In other words, retinoids might play a role in the maintenance of phenotypic and functional properties of mature neurons, hence extending beyond their well documented role in neurodevelopment. It is noteworthy that dysregulation in retinoid transcription events has also been considered as a potential etiological factor in neurodevelopmental diseases such as schizophrenia (Goodman, 1998) or in age-related neurodegenerative disorders such as Alzheimer's disease (Connor and Sidell, 1997).

The present results as well as previous studies on the functional significance of retinoid signaling lead us to conclude that a precise control of the level of retinoid signaling is of fundamental importance; "dysregulated genes" implicated would provide a potential target for therapeutic intervention. Furthermore, intervention directed at the level of nuclear receptors would be expected to produce a more long-lasting effect than would other cognitive enhancers. The efficacy of such cognitive enhancers is usually limited by their narrow therapeutic time window. This advantage is illustrated in the present study, because RA was administered between 18:00 and 19:00 hr whereas behavioral testing was performed the next day between 10:00 and 16:00 hr. Finally, although traditional cognitive enhancers, such as acetylcholinesterase inhibitors (Mohammed, 1993), were designed to restore the deficiency of neurotransmission of a specific type, retinoid receptortargeted drugs could potentially normalize a broad profile of gene expressions, thereby achieving a more global influence on the cellular homeostasis of the senescent brain.

\section{Conclusion}

The memory decline associated with normal aging is becoming a serious clinical issue among the populations of developed countries. Our study conducted in mice points to an altered regulation of the expression of selected genes as a potential cause of agerelated cognitive impairment. Specifically, our data suggest that brain retinoid-signaling hypof unction deserves further consideration as a key potential target for curative therapeutic attempts.

\section{REFERENCES}

Alfos S, Higueret P, Pallet V, Higueret D, Garcin H, Jaffard R (1996) Chronic ethanol consumption increases the amount of mRNA for retinoic acid and triiodothyronine receptors in mouse brain. Neurosci Lett 206:73-76.

Barnes CA (1994) Normal aging: regionally specific changes in hippocampal synaptic transmission. Trends Neurosci 17:13-18

Chelly J, Montarras D, Pinset C, Berwald-Netter Y, Kaplan JC, Kahn A (1990) Quantitative estimation of minor mRNAs by cDNApolymerase chain reaction. Application to dystrophin mRNA in cultured myogenic and brain cells. Eur J Biochem 187:691-698.

Chen YC, Chen QS, Lei JL, Wang SL (1998) Physical training modifies the age related decrease of GAP-43 and synaptophysin in the hippocampal formation in C57BL/6J mouse. Brain Res 806:238-245.

Chiang MY, Misner D, Kempermann G, Schikorski T, Giguere V, Sucov HM, Gage FH, Stevens CF, Evans RM (1998) An essential role for retinoid receptors $\operatorname{RAR} \beta$ and $\operatorname{RXR} \gamma$ in long-term potentiation and depression. Neuron 21:1353-1361.

Chiocca EA, Davies PJ, Stein JP (1989) Regulation of tissue transglutaminase gene expression as a molecular model for retinoid effects on proliferation and differentiation. J Cell Biochem 39:293-304.

Chomczynski P, Sacchi N (1987) Single-step method of RNA isolation by acid guanidinium thiocyanate-phenol-chloroform extraction. Anal Biochem 162:156-159.

Cohen NJ (1984) Preserved learning capacity amnesia: evidence for multiple memory systems. In: The neuropsychology of memory (Squire LR, Butters N, eds), pp 83-103. New York: Guilford.

Connor MJ, Sidell N (1997) Retinoic acid synthesis in normal and Alzheimer diseased brain and human neural cells. Mol Chem Neuropathol 30:239-252.

Corcoran J, Maden M (1999) Nerve growth factor acts via retinoic acid synthesis to stimulate neurite outgrowth. Nat Neurosci 2:4307-4308.

Dong JM, Li F, Chiu JF (1990) Induction of F9 differentiation by transient exposure to retinoic acid. Biochem Biophys Res Commun 170:147-152.

Eichenbaum H (1997) Declarative memory: insights from cognitive neurobiology. Annu Rev Psychol 48:547-572.

Eichenbaum H, Otto T, Cohen NJ (1992) The hippocampus: what does it do? Behav Neural Biol 57:2-36.

Enderlin V, Pallet V, Alfos S, Dargelos E, Jaffard R, Garcin H, Higueret $P$ (1997) Age-related decreases in mRNA for brain nuclear receptors and target genes are reversed by retinoic acid treatment. Neurosci Lett 229:125-129.

Etchamendy N, Desmedt A, Cortes-torrea C, Marighetto A, Jaffard R (1999) Contrasting effects of selective hippocampal lesion on different memory expression. The Fifth IBRO World Congress of Neuroscience Abstracts, p 75.

Etchamendy N, Enderlin V, Marighetto A, Pallet V, Higueret P, Jaffard $\mathrm{R}$ (2000) Evidence for a role of vitamin A in higher cognitive functions. Soc Neurosci Abstr 26:1748.

Gabrieli JD (1996) Memory systems analyses of mnemonic disorders in aging and age-related diseases. Proc Natl Acad Sci USA 93:13534-13540.

Gaetano C, Matsumoto K, Thiele CJ (1992) In vitro activation of distinct molecular and cellular phenotypes after induction and differentiation in a human neuroblastoma cell line. Cancer Res 52:4402-4407.

Gallagher M, Colombo PJ (1995) Ageing: the cholinergic hypothesis of cognitive decline. Curr Opin Neurobiol 5:161-168.

Geinisman Y, Detoledo-Morrell L, Morrell F, Heller RE (1995) Hippocampal markers of age-related memory dysfunction: behavioral, electrophysiological and morphological perspectives. Prog Neurobiol 45:223-252.

Goodman AB (1998) Three independent lines of evidence suggest retinoids as causal to schizophrenia. Proc Natl Acad Sci USA 95:7240-7244

Iñiguez MA, Morte B, Rodriguez-Pena A, Munoz A, Gerendasy D, Sutcliffe JG, Bernal J (1994) Characterization of the promoter region and flanking sequences of the neuron-specific gene RC3 (neurogranin). Mol Brain Res 27:205-214.

Jacobs S, Misner D, Evans RM, Stevens CF (2000) A novel role for 
vitamin A signaling in hippocampal long-term synaptic plasticity. Soc Neurosci Abstr 26:1118.

Johnson MK (1992) MEM: mechanisms of recollection. J Cognit Neurosci 4:268-280.

Kastner P, Mark M, Chambon P (1995) Nonsteroid nuclear receptors: what are genetic studies telling us about their role in real life? Cell 83:859-869.

Klein ES, Pino ME, Johnson AT, Davies PJ, Nagpal S, Thacher SM, Krasinski G, Chandraratna RA (1996) Identification and functional separation of retinoic acid receptor neutral antagonists and inverse agonists. J Biol Chem 271:22962-22966.

Korsching S (1993) The neurotrophic factor concept: a reexamination. J Neurosci 13:2739-2748.

Krezel W, Kastner P, Chambon P (1999) Differential expression of retinoid receptors in the adult mouse central nervous system. Neuroscience 89:1291-1300.

Maden M, Gale E, Zile M (1998) The role of vitamin A in the development of the central nervous system. J Nutr 128:471S-475S.

Malik MA, Blusztajn JK, Greenwood CE (2000) Nutrients as trophic factors in neurons and the central nervous system: role of retinoic acid. J Nutr Biochem 11:2-13.

Mangelsdorf DJ (1994) Vitamin A receptors. Nutr Rev 52:S32-S44.

Marighetto A, Etchamendy N, Touzani K, Torrea CC, Yee BK, Rawlins JN, Jaffard R (1999) Knowing which and knowing what: a potential mouse model for age-related human declarative memory decline. Eur J Neurosci 11:3312-3322.

Marighetto A, Touzani K, Etchamendy N, Torrea CC, De Nanteuil G, Guez D, Jaffard R, Morain P (2000) Further evidence for a dissociation between different forms of mnemonic expressions in a mouse model of age-related cognitive decline: effects of tacrine and S 17092, a novel prolyl endopeptidase inhibitor. Learn Mem 7:159-169.

McNaughton BL, Morris RGM (1987) Hippocampal synaptic enhance- ment and information storage within a distributed memory system. Trends Neurosci 10:408-415.

Mohammed AH (1993) Effects of cholinesterase inhibitors on learning and memory in rats: a brief review with special reference to THA. Acta Neurol Scand Suppl 149:13-15.

Nicolle MM, Gallagher M, McKinney M (1999) No loss of synaptic proteins in the hippocampus of aged, behaviorally impaired rats. Neurobiol Aging 20:343-348.

Pak JH, Huang FL, Li J, Balschun D, Reymann KG, Chiang C, Westphal $\mathrm{H}$, Huang KP (2000) Involvement of neurogranin in the modulation of calcium/calmodulin-dependent protein kinase II, synaptic plasticity, and spatial learning: a study with knockout mice. Proc Natl Acad Sci USA 97:11232-11237.

Pedersen WA, Berse B, Schuler U, Wainer BH, Blusztajn JK (1995) All-trans- and 9-cis-retinoic acid enhance the cholinergic properties of a murine septal cell line: evidence that the effects are mediated by activation of retinoic acid receptor-alpha. J Neurochem 65:50-58.

Rogue PJ, Ritz MF, Malviya AN (1993) Impaired gene transcription and nuclear protein kinase $\mathrm{C}$ activation in the brain and liver of aged rats. FEBS Lett 334:351-354.

Rylett RJ, Williams LR (1994) Role of neurotrophins in cholinergicneurone function in the adult and aged CNS. Trends Neurosci 17:486-490.

Tamaru M, Yoneda Y, Ogita K, Shimizu J, Nagata Y (1991) Age-related decreases of the $N$-methyl-D-aspartate receptor complex in the rat cerebral cortex and hippocampus. Brain Res 542:83-90.

Wallenstein GV, Eichenbaum H, Hasselmo ME (1998) The hippocampus as an associator of discontiguous events. Trends Neurosci 21:317-323.

Younkin DP, Tang CM, Hardy M, Reddy UR, Shi QY, Pleasure SJ, Lee VM, Pleasure D (1993) Inducible expression of neuronal glutamate receptor channels in the NT2 human cell line. Proc Natl Acad Sci USA 90:2174-2178. 